\title{
EFFECTIVENESS OF AN EXERCISE REGIME ON THE REHABILITATION OF CHRONIC OBSTRUCTIVE LUNG DISEASE PATIENTS USING HEART-RATE AS THE PARAMETER
}

\author{
Tudor HALE, Dip.P.E.," Jean SPRIGGS, B.Sc.,"* and E. J. HAMLEY, Ph.D. \\ Human Biology Laboratory, Loughborough University of Technology
}

Investigations of exercise regimes as a prescribed therapeutic procedure for cardio-respiratory cripples has only recently been related to specific diagnostic conditions. Laros \& Swierenga, 1972, have shown that many of these patients lead needlessly restricted lives and that patients with Chronic Obstructive Lung Disease ("C.O.L.D.") can benefit from a rehabilitation programme using a progressive exercise regime. The difficulties involved in these investigations are to set up suitable physiological experiments, the design of the exercise regime and the selection of appropriate control conditions.

This study, by including more rigidly controlled conditions, sets out to examine the effects of a short period of progressive exercise therapy on the physiological responses to progressive work tests of a group of men with chronic obstructive lung disease and low work tolerance. Heart and work rate data only are presented here, the remaining information will be published later.

\section{METHODS AND MATERIALS}

Eleven men, referred by their physicians, took part in the study and were divided into an experimental ( $E, N=$ 6) and a control group (C, $N=5)$. Their vital statistics appear in Table $\mathbf{I}$.

\section{TABLE I}

Anthropometric data of the two groups (means and SD's)

$\begin{array}{lcccc} & \text { Age } & \text { Ht } & \text { Wt 1 } & \begin{array}{l}\text { Wt 2 } \\ \text { (Post } \\ \text { training) } \\ \text { kg }\end{array} \\ \text { Group E } & \text { years } & \text { cms } & \text { kg } & \\ \text { S }= & 60.9 & 170.0 & 63.4 & 63.1 \\ \text { Group C } & 6.29 & 3.89 & 8.33 & 7.27 \\ \text { S }= & 63.4 & 171.1 & 57.8 & 58.5 \\ & 8.89 & 7.66 & 15.50 & 17.02\end{array}$

FOOTNOTE:

- Present address: Bishop Otter College, Chichester

* Present address: Midhurst Medical Research Centre, Midhurst
Preliminaries: Before the first work test patients were taught to breathe through the mouthpiece - valve box and asked to practise the procedure at frequent intervals (5 minutes each hour was suggested) during the day. Resting electrocardiograms, lung function and habitual activity patterns were also recorded prior to training.

Work Test: Patients were tested on two devices; an electronically braked cycle ergometer (Elema-Schönander) and a variable speed and gradient treadmill (Glieze-Ramball). Group $E$ was tested on three occasions; a) prior to an habituation programme; b) immediately after habituation; c) post-training. Group C was tested on the last two occasions only. Cycle ergometer and treadmill tests were administered on successive days; the cycle was always the first device used.

Information derived from the tests consisted of $\mathrm{V}_{T}$, $\mathrm{FEO}_{2}, \mathrm{FECO}_{2}, \mathrm{FEO}_{2} \mathrm{ET}_{\mathrm{C}}, \mathrm{FECO}_{2} \mathrm{ET}$, per breath, and $f_{H}, f_{R}, v_{E}, \dot{V}_{\mathrm{O}_{2}}$ and $\dot{V}_{\mathrm{CO}_{2}}$ per minute. Full details of the procedures can be obtained elsewhere from standard textbooks (e.g. Åstrand and Rodahl, 1971, etc.).

Habituation: The habituation programme lasted three days and consisted of intermittent treadmill walking at zero grade. Actual walking time never exceeded 60 seconds per repetition, at a speed below that of the work test, and was followed by 60 seconds rest. Patients were encouraged to walk with longer strides and without holding on to the rails. Total work time was less than 10 minutes per session and there were two sessions per day.

Training: Both groups took part in training programmes consisting mainly of intermittent treadmill walking but differing in duration and intensity. Training for group $E$ was designed to last for $\mathbf{3 0}$ minutes a day, five times a week for about a month. The initial work load set, though sub-maximal, was high enough to raise $f_{H}$ above a calculated minimum threshold level. This minimum training heart rate $\left(f_{H_{t}}\right)$ was calculated according to the formula given below (Roskamm, 1967). 


$$
f_{H_{t}}=f H_{\max }-f_{H_{\text {rest }}} \times 70 / 100+f_{H_{\text {rest }}}
$$

$\mathrm{f}_{\text {max }}$ was taken as the highest heart rate achieved during the work tests, and $f_{H_{\text {rest }}}$ was the mean sleeping $\mathrm{f}_{\mathrm{H}}$ recorded by SAMI/HR device. Work rate was increased as patient tolerance improved.

The duration and intensity of training for group $\mathrm{C}$ was less; training time was less than 10 minutes per session and the intensity such that $\mathrm{f}_{\mathrm{t}}$ was seldom exceeded. In addition loads remained constant throughout the programme.

\section{RESULTS}

The experimental group completed 110 training sessions, with a mean training time of $\mathbf{3 0 . 6}$ minutes per session. With one exception (E2) $f_{H_{t}}$ exceeded threshold levels on all but four occasions. Training sessions for the controls were fewer (73) and shorter (mean time 5.0 minutes), but more importantly $\mathrm{f}_{\mathrm{t}}$ for this group was below threshold on all but four occasions. Individual responses during training are shown in fig. 1 .

Comparison of the group responses (see figure 2) reveals a similar pattern. The mean $f_{H}$ achieved by group $E$ was 111 b.min ( $96 \%$ of maximum rate), higher than the calculated minimum of 103 b.min $189 \%$ of $\left.f_{H_{\max }}\right)$. Calculated minimum $\mathrm{fH}_{\mathrm{t}}$ for group $\mathrm{C}$ was 98 bt.min $\left(91 \% \mathrm{f}_{\mathrm{H}_{\text {max }}}\right)$ but the mean level achieved was only 91 b.min; only on the first training session did mean $f_{H_{t}}$ exceed the threshold and then by less than 5 b.min.

Changes in working time, work and $\mathrm{f}_{\mathrm{max}}$ for each individual during the work tests are shown in figure 3 .

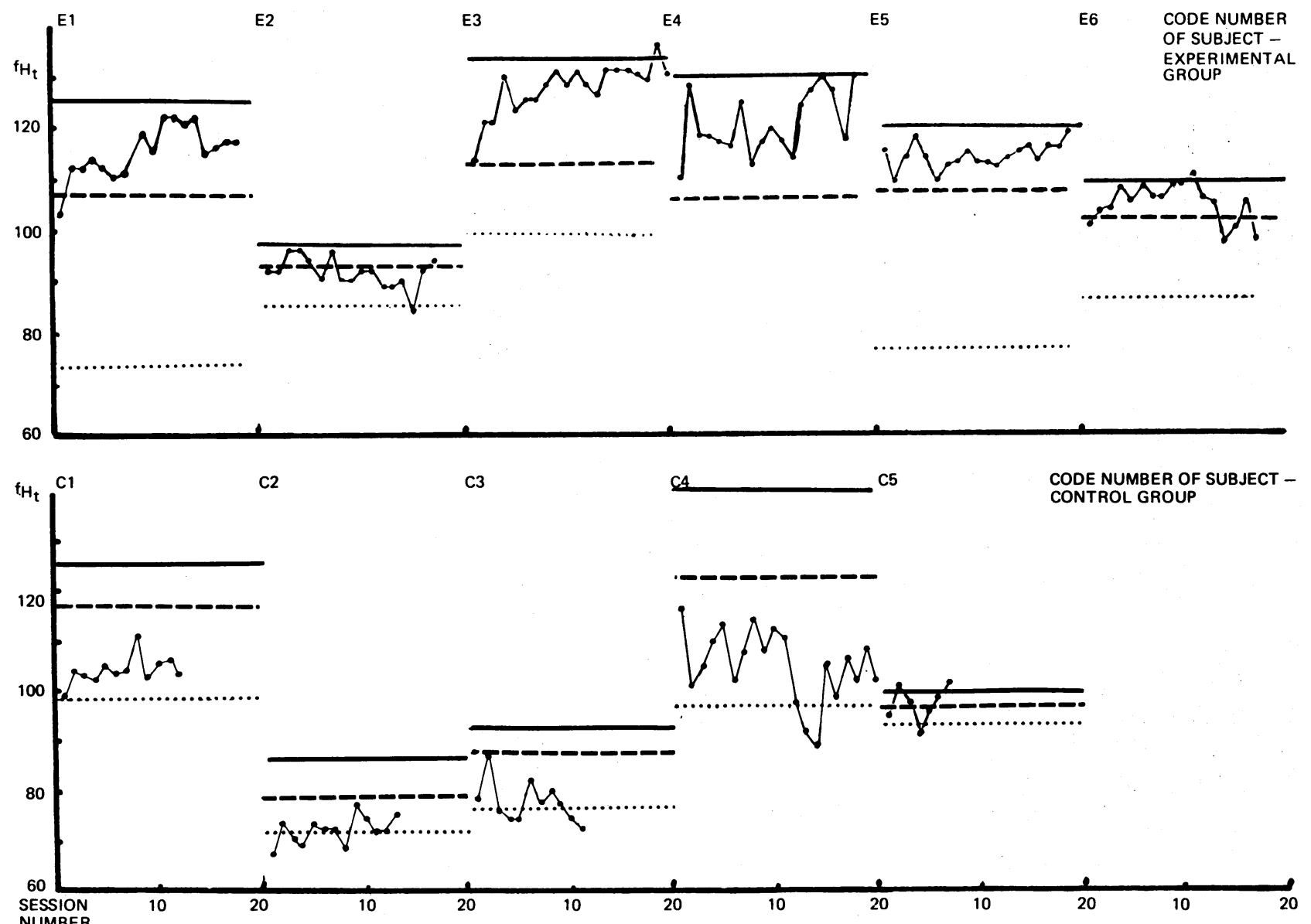

Fig. 1. Individual Heart Rate Responses During Training Sessions (see fig. 2 for Key to Symbols) 


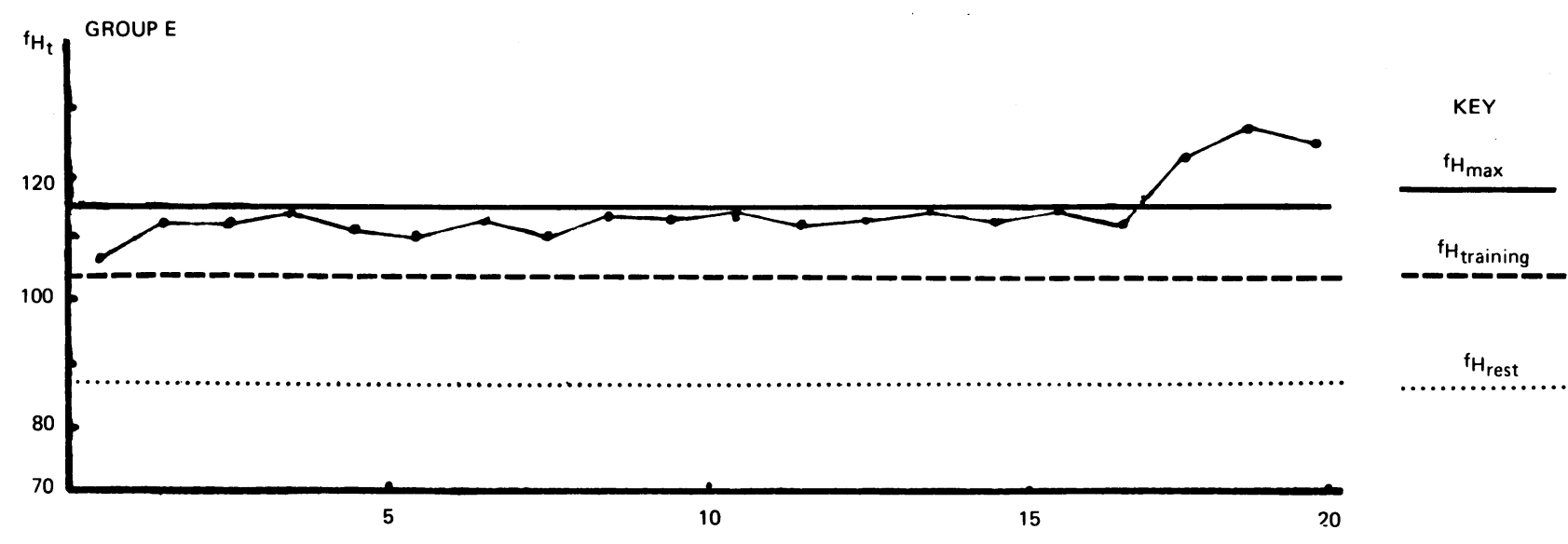

GROUP C

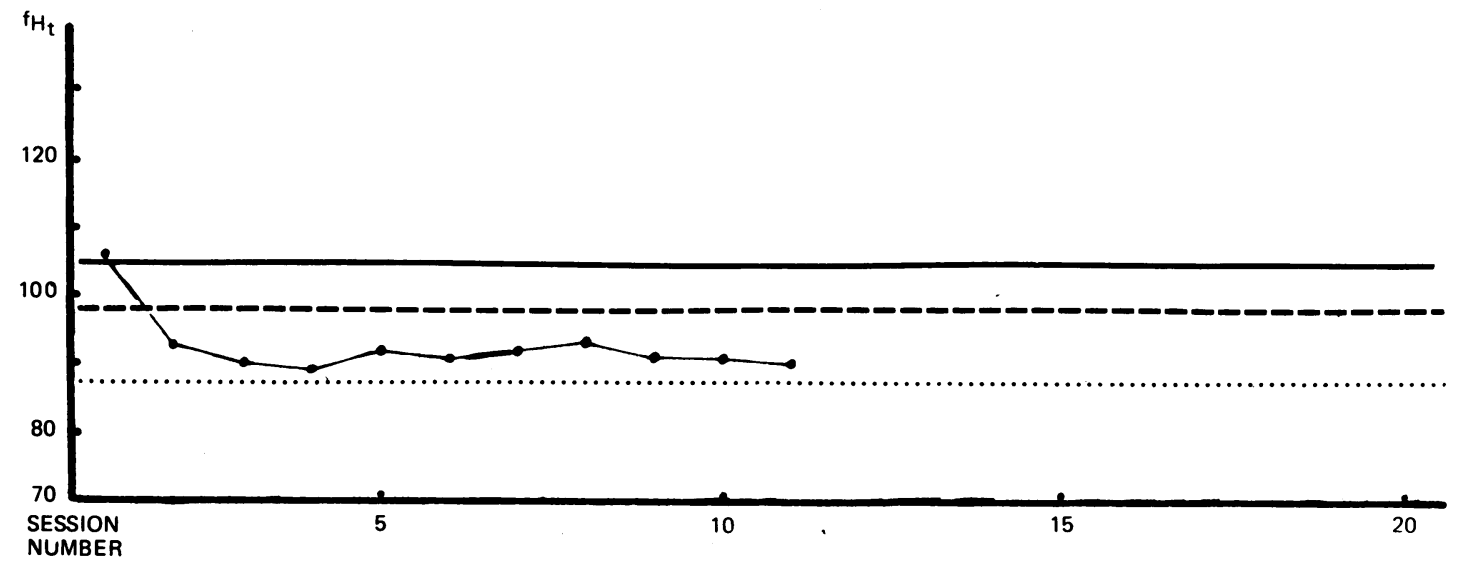

Fig. 2. Mean Heart Rate of the Groups During Training

All six experimental subjects increased treadmill work time, mean improvement being 163 seconds (573 - 736 s). Only three controls were able to undergo the post-training test; one increased walking time but mean time rose by only 19 seconds ( $477-496 \mathrm{~s}$ ).

Working time on the cycle ergometer was increased by five of group $E$ but the mean improvement - 109 seconds $(562-671 \mathrm{~s})$ - was less than that seen on the treadmill in spite of similar pre-training times on the two devices. Three of the five controls also showed small increases but the mean result showed a reduction of 48 seconds (398 - 350 s). Total work done rose for group E from $385-513 \mathrm{~W}$ but fell for group $C$ from $234-$ $192 \mathrm{~W}$.

Individual post-training treadmill $\mathrm{f}_{\mathrm{H}_{\max }}$ for group $\mathrm{E}$ were either lower or unchanged in all six cases, leading to a small decrease in mean level $(115-112$ b.min). Only one of the three controls had lower post-training $\mathrm{f}_{\mathrm{max}}$ and the mean remained virtually unchanged (106 - 107 b.min). The bicycle test results for group $E$ were variable; three had lower $\mathrm{fH}_{\text {max }}$, two had higher and one remained identical and the mean rate was practically unchanged (114 - 115 b.min). No member of the control group showed increased $\mathrm{f}_{\mathrm{H}_{\text {max }}}$ and the mean figure fell $(107-101$ b. $\mathrm{min})$.

\section{DISCUSSION}

The pessimistic view that little effective action can be taken to improve the exercise tolerance of COLD patients is not wholly supported by the evidence from this study. The actual improvements in working time (2.5 min on treadmill, $1.75 \mathrm{~min}$ on cycle) may seem small but represent considerable mean percentage increases (28 and 19\% respectively) over pre-training results and are seen by the patients as tangible rewards for the notable efforts made. Even more important 

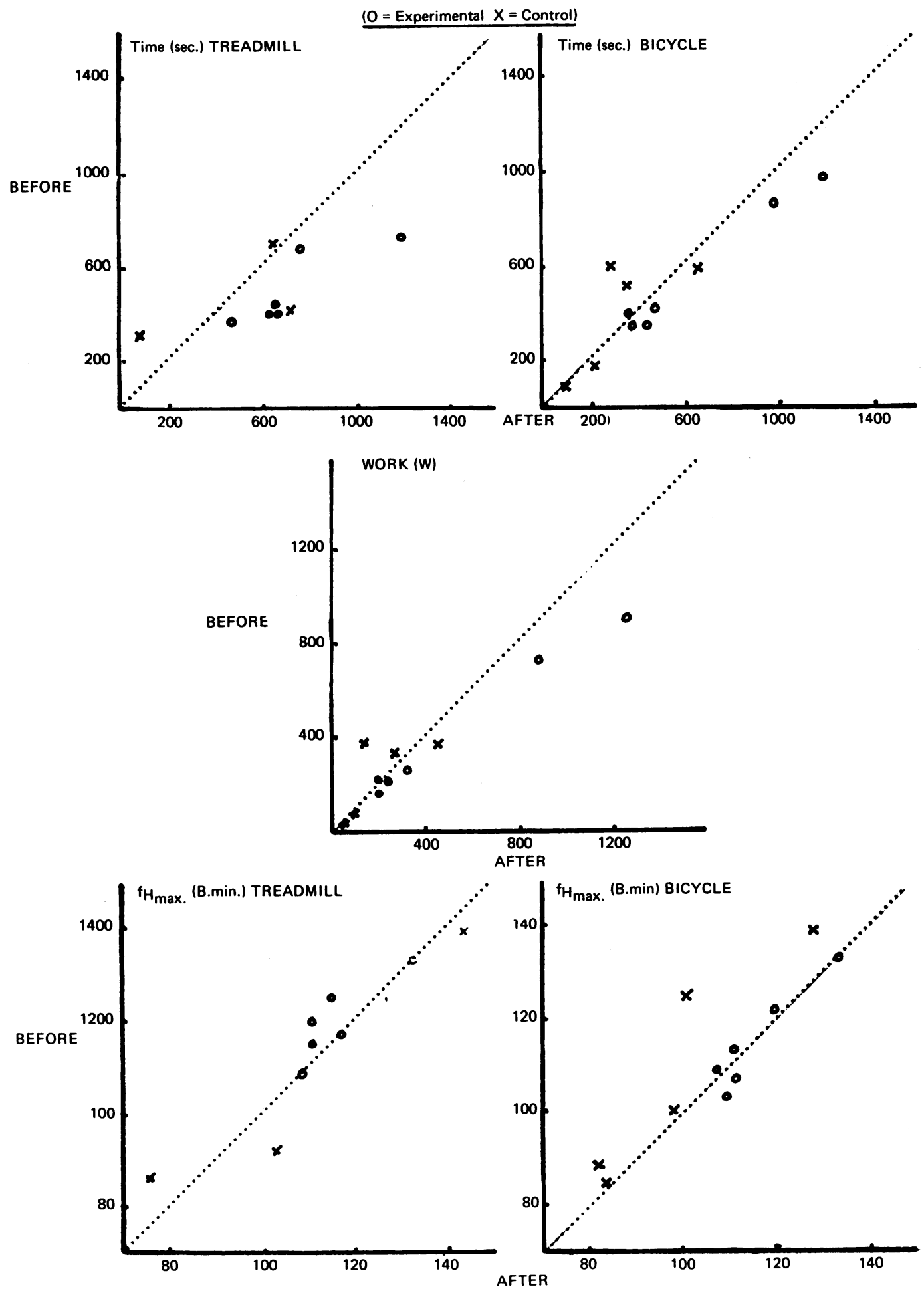

Fig. 3. Changes in Individual Working Time and Rate, and Heart Rate After Training 
perhaps than the increase in work capacity is the frequently expressed view that the programme produced enhanced confidence, that everyday activities of living are accomplished more easily and that activity previously avoided is approached in a more realistic way. For many patients this improvement in the quality of life is a worthwhile objective to be striven for, and may also be seen as an appropriate clinical objective.

In addition the study throws some light on the training methods that can be employed in exerciseorientated rehabitation programmes. Clearly even the minimal increase in control group activity, combined with the greater degree of daily attention the programme entailed, was sufficient to produce increases in work capacity in some cases. But it is also apparent that the more consistent changes occured when $f_{H}$ was maintained above individually calculated minimum levels, for approximately $\mathbf{3 0}$ minutes per day, over a period of about a month. These procedures are reminiscent of the principles of training laid down by Karvonen et al (1957) for normal subjects, and, if Roskamm's formula for calculating minimum intensity is modified to take account of the low $\mathrm{fH}_{\text {max }}$ of COLD patients, a clear procedure emerges for prescribing training programmes for individual subjects.

Even so it is difficult to ignore suggestions (Harrison \& Reeves, 1965; Clausen et al, 1969) that the initial value of any exercise programme is the psychological reassurance which develops. It is possible, perhaps certain, that the increased working time of each individual reflects psychological as well as physiological adjustments to activity. Equally it is impossible to judge precisely which of the two adjustments is chiefly responsible for increased exercise tolerance, but it is worth noting that $\mathrm{f}_{\mathrm{t}}$ remained fairly steady (i.e. a daily variation of less than 5 b.min - see fig. 2) for both groups. As far as the controls are concerned this is hardly surprising since work rate remained virtually constant throughout, but the uniformity shown by group $E$ occurred against a background of increasing work. Mean treadmil! speed increased from $3.0 \mathrm{~km}$. hr during the first week of training to $4.1 \mathrm{~km}$. $/ \mathrm{hr}$ in the final week and the mean gradient increased from $4.2^{\circ}$ to $8.0^{\circ}$.

This suggests enhanced cardiac function, a suggestion supported by post-training $\mathrm{f}_{\mathrm{max}}$ results. The mean treadmill work time of group $E$ increased $28 \%$ whereas the mean $\mathrm{fH}_{\text {max }}$ fell slightly, and a $19 \%$ improvement in pedalling time was achieved with practically the same mean $f_{H_{\max }}$. The controls on the other hand demonstrated no change in cardiac function; treadmill walking time rose by less than $1 \%$ and was accompanied by a similar rise in heart rate, and although $\mathrm{fH}_{\max }$ was lower on the cycle so was the work rate. Undoubtedly the $28 \%$ increase in treadmill time noted above reflects some improved treadmill walking technique but improvement on the cycle also indicates that the training programme produced general as well as specific effects.

\section{ACKNOWLEDGEMENTS}

We are most grateful to Dr. Gordon Cumming, Director of the Midhurst Medical Research Centre for his encouragement and for providing facilities and patients for this study.

\section{REFERENCES}

Åstrand, P. O. and Rodahl, K (1971). Textbook of Work Physiology, Reinholt, London.

Clausen, J. P., O. A. Larsen, J. Trap-Jensen (1969). Physical training in management of coronary artery disease. Circulation, 40, 143-154.

Harrison, T. R. and T. J. Reeves (1965). The psychologic management of patients with cardiac disease. Am. Heart J., 70, 136.

Laros, C. D. and J. Swierenga (1972). Rehabilitation programme in patients with obstructive/destruction lung disease. Respiration, 29, 344-58.

Roskamm, H. (1967). Optimum patterns of exercise for healthy adults. Canad.Med.Ass.J., 19, $12,895$. 